\title{
enorden
}

\section{Does the Nordic Model need to change?}

Overview of the research report, The Nordic model - challenged but capable of reform

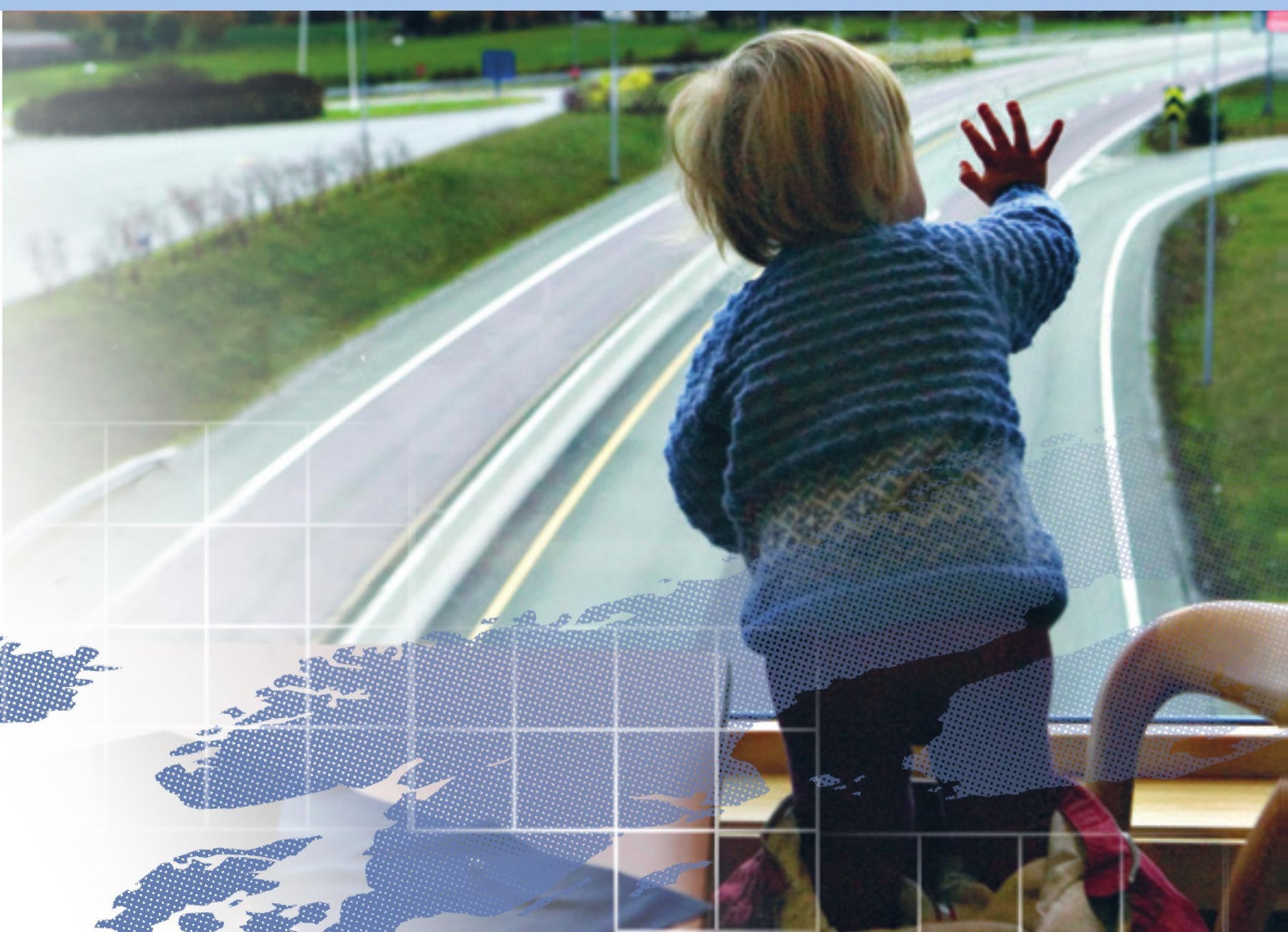


ISBN 978-92-893-3884-4 (PRINT)

ISBN 978-92-893-3885-1 (PDF)

http://dx.doi.org/10.6027/ANP2014-772

ANP 2014:772

(C) Nordic Council of Ministers 2014

Production and text: Arvidsson Kultur \& Kommunikation, Malmö Editors of the original report, The Nordic model - challenged but capable of reform: Tarmo Valkonen and Vesa Vihriälä Contributors to the original report: Karsten Albæk, Torben M. Andersen, Rita Asplund, Erling Barth, Bernt Bratsberg, Lars Calmfors, Antti Kauhanen, Jukka Lassila, Mika Maliranta, Niku Määttänen, Oddbjørn Raaum, Knut Røed, Kristine von Simson, Allan Sørensen, Tarmo Valkonen, Pekka Vanhala and Vesa Vihriälä Layout: Erling Lynder Cover photo: Karin Beate Nøsterud/norden.org Print: Rosendahls-Schultz Grafisk Copies: 500

www.norden.org/en/publications

Printed in Denmark

This publication has been published with financial support from the Nordic Council of Ministers. However, the contents of this publication do not necessarily reflect the views, policies or recommendations of the Nordic Council of Ministers.

\section{Nordic Council of Ministers \\ Ved Stranden 18 \\ DK-1061 Copenhagen K \\ Telephone (+45) 33960200}

www.norden.org

\section{Nordic co-operation}

Nordic co-operation is one of the world's most extensive forms of regional collaboration, involving Denmark, Finland, Iceland, Norway, Sweden, and the Faroe Islands, Greenland, and Åland.

Nordic co-operation has firm traditions in politics, the economy, and culture. It plays an important role in European and international collaboration, and aims at creating a strong Nordic community in a strong Europe.

Nordic co-operation seeks to safeguard Nordic and regional interests and principles in the global community. Common Nordic values help the region solidify its position as one of the world's most innovative and competitive. 


\section{(1) nordon}

\section{Does the Nordic Model need to change?}

Overview of the research report, The Nordic model

- challenged but capable of reform

\section{Foreword}

The Nordic Model

The three challenges

Focus areas for future reform

Weaknesses and strengths of the Nordic countries, and reform proposals 


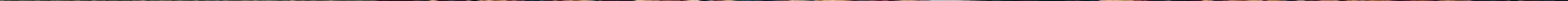




\section{Foreword}

This publication is a brief, independent overview of a comprehensive research project about the Nordic Model and its future sustainability.

Does the Nordic Model exist? If so, what challenges is it facing? And can it be reformed and adapted to societal changes? The main report, The Nordic model - challenged but capable of reform, is part of the "Sustainable Nordic Welfare" programme, financed by the Nordic
Council of Ministers and initiated by the Nordic employer associations. The aim of the original research report was to provide the Nordic governments with tools for managing the welfare challenges the Nordic countries will be facing in the future.

ETLA, the Research Institute of the Finnish Economy, collaborated with other researchers and universities in the Nordic region in drawing up the report.
We hope that this brief overview and the more in-depth main report will not only inspire a Nordic debate on welfare issues, but also contribute to the international debate regarding the Nordic region and our welfare systems.

Dagfinn Høybråten Secretary General Nordic Council of Ministers 
In recent years, the Nordic Model has been attracting great international attention. The Nordic countries have been portrayed as being particularly successful in the way they have tackled the consequences of the global financial crisis. The societal concept has been proposed as a role model for other countries. The harmonious combination of an extensive welfare state, well-managed public finances, and a successful market economy has led to the model being given the epithet, "the next supermodel" by The Economist magazine. This stand-alone publication provides an overview of the main points from the research report, The Nordic model - challenged but capable of reform. In the report, Nordic researchers gave their views on the Nordic Model and its challenges, and proposed how it could be adapted in the coming years. 


\section{The Nordic Model}

Despite its good reputation globally, the Nordic region is facing many problems and challenges. The Nordic countries came through the financial crisis relatively unscathed, but were not spared its effects. Has the Nordic Model really been as successful in the way it has often been described? Can its success continue into the future, or is the model insufficient and inadequate in the era of globalisation?

What is so unique in the Nordic Model?

\section{The traditional image of} the Nordic Model is a welfare state characterised by a large public sector that provides its citizens with generous benefits, welfare services and a social safety net.

The traditional image of the Nordic Model is a welfare state characterised by a large public sector that provides its citizens with generous benefits, welfare services and a social safety net. At the same time, the Nordic countries have been careful to maintain strong public finances. The labour market is highly regulated by collective agreements, education is free and generally of high quality, and a lot of tax revenue is invested in research and development. The Nordic countries have been open to free trade and technological changes. Other successes are a high standard of living, high levels of employment, relatively small differences in income, and a high level of gender equality.

This is the image. How well does it match reality? One way of examining this is by comparing data from the Nordic countries with other European countries and the US.

The Nordic region has been able to retain high levels of GNP per capita, and is only surpassed here as a group by the US. A look at income distribution confirms that this affluence is still relatively evenly distributed among the population. Income differences are small - here the countries form a clearly distinct group in Europe, and the only countries that come close in terms of income differences are Germany, France, the Netherlands, Austria and Belgium.

The Nordic region is characterised by a high level of employment, and women and elderly people are well represented. However, there are certain differences between the countries - employment levels in Finland and Denmark are lower compared to the other Nordic countries. The labour markets are characterised by a "flexicurity" model with relatively liberal terms of employment and a focus on activation measures for unemployed people. Trade unions seem relatively strong - nearly 70 percent of Nordic employees are members, which is a much higher figure than anywhere else, but the proportion of employees covered by collective agreements is no higher than in many other European countries.

The impression that a lot of resources are invested in 
research and development does match reality, particularly in the cases of Sweden and Finland.

One of the hypotheses as to why the financial crisis was less serious in most of the Nordic countries concerns the strong public finances. All countries except Iceland have been able to maintain manageable debt levels, which are among the lowest in Europe, but it is difficult to find evidence of this being due to similar Nordic economic policies.

The Nordic countries are always near the top of surveys measuring trust, regardless of whether this concerns trust in other people, politicians or the legal system.

Is the public sector in the Nordic countries particularly large? What does suggest this is that a large proportion of the population is employed in the public sector, and the Nordic countries still have somewhat greater tax revenues in relation to GNP compared with other countries. On the other hand, Nordic countries no longer stand out from many other European countries in terms of, for example, public expenditure and level of unemployment benefits.

One particularly surprising finding is that redistribution through taxes and transfers is not particularly great, although this can probably be explained by the high levels of employment in the Nordic countries, which reduce the need for such measures.

Nordic countries vary a great deal in these aspects - Iceland has the smallest public sector in terms of both tax level and the proportion of employees in the public sector, while Norway and Sweden have lower levels of benefits than the others.

\section{Trust - unparalleled in the world}

One area in which the Nordic region particularly stands out is the high degree of trust. The Nordic countries are always near the top of surveys measuring trust, regardless of whether this concerns trust in other people, politicians or the legal system.

Consequently, it still seems to be legitimate to talk about a special Nordic Model. Gender equality, small differences in income, strong institutions and the high level of general trust create strong conditions for a smooth-running society, within the framework provided by a combination of a comprehensive social safety net and a dynamic market economy.

\section{No longer so unique}

The Nordic region is not as unique in Europe as it once was. There are now bigger differences between the individual Nordic countries, and the Nordic region as a whole now displays great similarities with other European countries in certain areas. True, the Nordic region is still characterised by a large public sector in combination with high tax levels, but this is no longer specifically Nordic, and there are great similarities with countries like France, Germany and the Netherlands. 


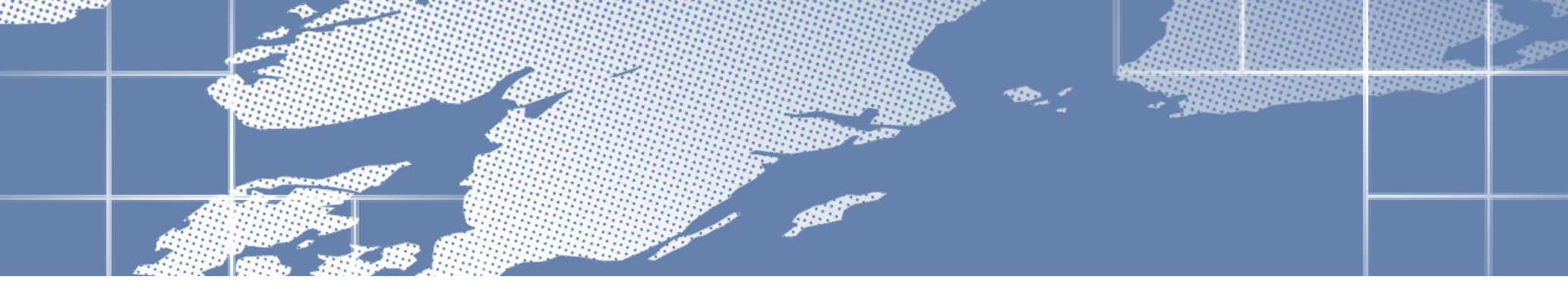

The Nordic Model has not always been held in such high regard.

After a very successful post-war period, the Nordic economies passed through a darker phase between the 1970s and the financial crises of the early 1990s. During this time, the Nordic Model was often regarded as outdated. In the 1990s, the Nordic region recovered, and the period until the start of the global financial crisis in 2008 was very successful. Deregulations, tax reforms, a smooth-running labour market and an increase in overall demand have been suggested as contributory factors. However, increasing demand can, to some extent, be explained by higher debt levels, particularly in the cases of Iceland and Denmark.

\section{The Nordic region has not} come through the most recent financial crisis as well as it has often been portrayed.

The Nordic region has not come through the most recent financial crisis as well as it has often been portrayed. The region has performed better than Southern Europe, but other West European countries show better figures on average - even if we exclude Iceland with its more drastic problems. This applies regardless of whether GNP, unemployment or employment are measured. However, the Nordic countries have, without doubt, been more successful at keeping national debt under control.

The crisis had varying impact on the Nordic countries. Iceland was hit particularly hard, and the collapse of the inflated bank sector led to a very serious crisis from which the country has still not fully recovered. GNP has grown, but public finances are still in a poor state. Finland was also hit badly, and current GNP is still 5.2 percent below the 2008 level - the weakest growth in the Nordic region. This is mainly attributable to the decline in key sectors, particularly information and communication technology. Denmark has also struggled to recover from a recession that was exacerbated by a housing bubble, and the country has performed least well in terms of unemployment.

In contrast, Norway and Sweden have coped much better, and GNP levels have risen above the figures in 2008. Norwegian growth can largely be explained by a continual flow of revenues from the country's natural resources. Sweden has probably benefitted from labour market reforms, tax reductions, and less generous sickness benefit systems. It has also been helped by a more diverse economy, particularly compared with Finland. 


\section{The three challenges}

The Nordic Model is already under challenge, and the pressure will increase because of three megatrends: the digital revolution, globalisation, and increasing life expectancy.

\section{Analyses suggest that every third, or maybe even every second, job will be at risk in the next ten to twenty years.}

\section{The digital revolution}

Increasingly powerful digital technology may cause many of today's workplaces to disappear. It will not only be the simple, routine jobs under threat, but also jobs that need sophisticated professional skills. Analyses suggest that every third, maybe even every second, job will be at risk in the next ten to twenty years. Here, the private sector will be more vulnerable than the public sector. The jobs that will disappear will be mostly those involving low and mid-level salaries, while new jobs created will be at the upper or lower ends of the salary scale. Those who will benefit from the changes are people who own or are skilled in the new technology. New service jobs will be created, but these are seldom well-paid, so the polarisation of the labour market already observed today in many countries will probably continue. Differences in income will continue to grow, which will have social consequences and could have a negative impact on societal trust.

\section{Globalisation}

It will become increasingly difficult to maintain a large public sector and thereby a high tax burden, as national boundaries will become less significant and businesses and people will become more mobile. Companies will locate their head offices and business activities in countries where costs are most favourable. An increasing share of production will take place in international value chains controlled by transnational enterprises. Companies will be able to fine-tune their tax liabilities by locating selected parts of their production in countries with the lowest tax rates. Already today, many Nordic companies have most of their labour force outside their home countries.

\section{Businesses will be able to fine-tune their tax liabilities by locating selected parts of their production in countries with the lowest tax rates.}

Even the highly-qualified labour force will become more mobile; global companies and networks, improved language skills, similar educational programmes and lifestyles weaken the links between people and a particular country. Competition between countries will increase, and great efforts will be made at national level to attract businesses and skilled labour, not least through lower taxes. Keeping the costs of businesses competitive, while creating and maintaining good living conditions for the skilled workforce, are therefore key factors in retaining production in the Nordic countries. 
- SHOW BUSINESS

- NETWORK

- MUSIC

- CINEMA

- BUSINESS/FINANCE - WORLD NEWS
12010111010101001 0010101010100101 14010.0 11. tosto: 1040101101 1481314000103041 10 110 10 111 1010.101011010mero 1100111110101
12010111010101001 0010101010100101 110.9101110010101 101101010101101

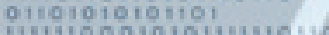
10110101111

10101110101101011010 O1100111110101 01101010 111111

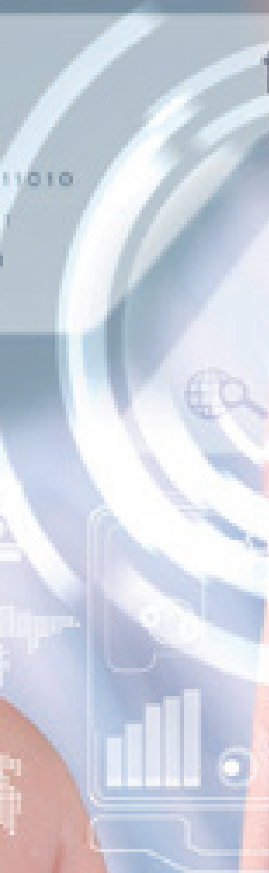

1010110110

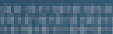
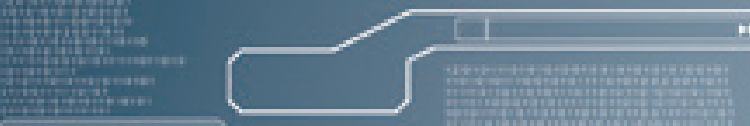

WORLD

站4 $(x+2,-x+2)$
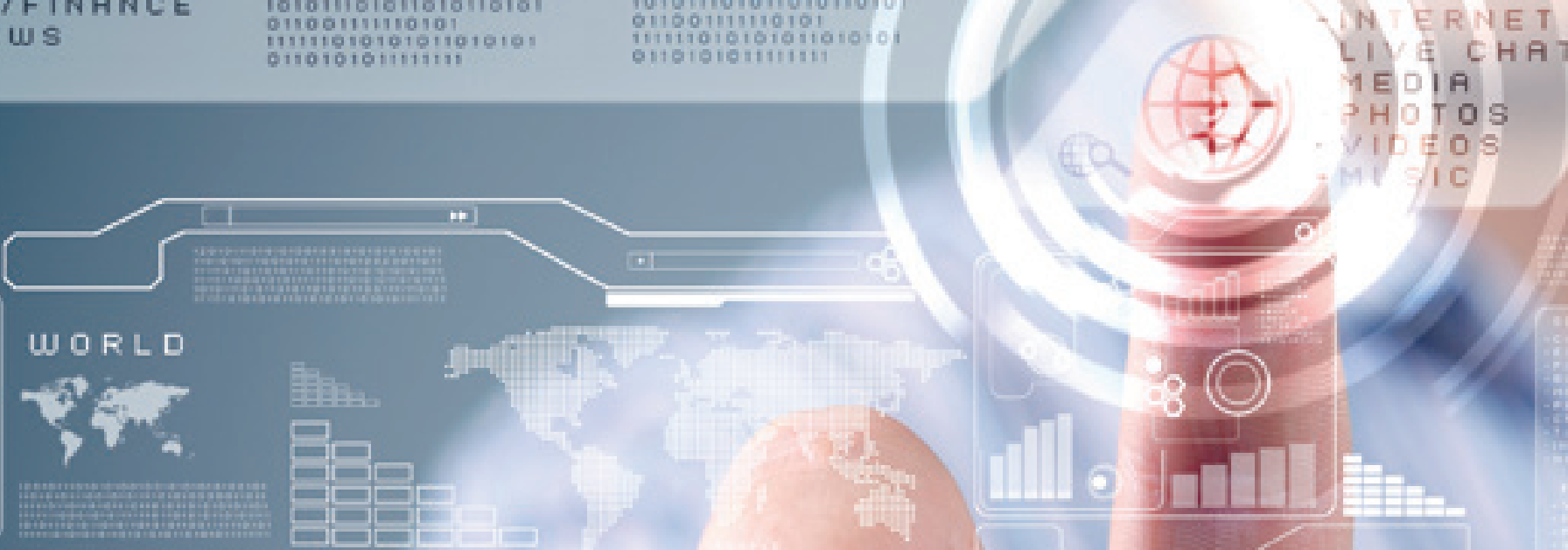
1EDIA
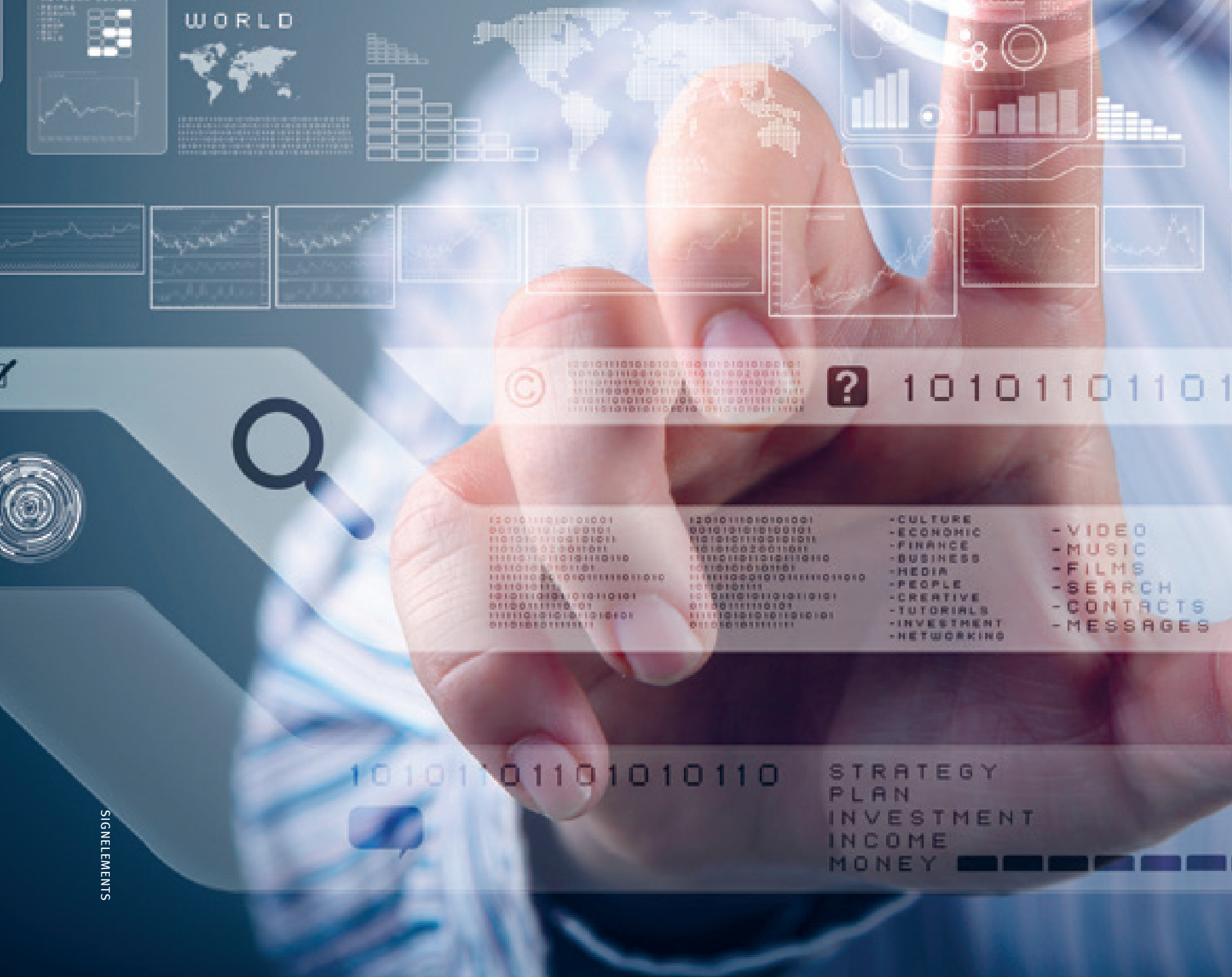

STRATEGY

PLAN

INVESTMENT

INCOME

MONEY

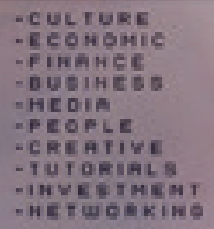

$-V I D E O$

- MUSIC

- FILMS

- SEARCH

- CONTACTS

- MESSAgES 


\section{Increasing life expectancy}

Average life expectancy continues to rise. The broadening at the top of the population pyramid is not fully compensated at the lower end, either by increasing birth rate or greater immigration. The result is that the proportion of the population that is of working age will decrease or, expressed another way, the proportion of dependent population will increase. A smaller number of people will have to support the ageing population, which will put pressure on public finances.

\section{A smaller number of people will have to support the ageing population, which will put pressure on public finances.}

The challenge will be especially great for the Nordic welfare models with their generous transfer systems. Here, the tradition is that the public sector is universal in its mission to take care of the old, sick and vulnerable members of society. Moreover, the situation will be exacerbated if certain population groups are excluded from the labour market and find it difficult to find productive employment.

Two factors make the Nordic countries particularly vulnerable to these three global trends.

Firstly, the expectation that the state will provide citizens with welfare services is deeply rooted in Nordic societies, so the costs of this are expected to rise. One reason for this is the Wagner Effect, which states that demand for public services expressed as a proportion of GNP increases as an economy develops and GNP rises. The second effect is Baumol's Cost Disease, which states that the cost of welfare services comprises an increasing proportion of GNP, because productivity in service professions develops more slowly than in production of goods.

The second factor is that the Nordic countries have small, open economies, sensitive to shocks in their highly specialised export industries. It can be difficult to recover from a recession, something that Finland in particular has experienced since the most recent crisis.

Within the care sector, more diseases will

be treatable, and increasingly costly medical technology will be developed. Who will be given care? Who will pay?
A high level of skills has been a strong contributory factor to high productivity in the Nordic countries, so the shortcomings shown in the national educational systems at all levels are worrying. The latest PISA educational results are very disappointing for the Nordic region, with the notable exception of Finland. Very few Nordic universities appear near the top of international rank- ings. Of the fifty highest-ranked universities in a Chinese survey 



\section{Focus areas for future reform}

The question now is how the Nordic region will successfully manage the three major challenges: the digital revolution, globalisation, and increasing life expectancy. These trends will eradicate jobs, increase inequality, increase public expenditure, reduce tax revenues, and make economies more unstable. Will the Nordic Model even be able to survive, let alone develop under these circumstances?

Naturally, it is not possible to give a definitive answer to this question, but the answer could nevertheless be a qualified yes. The Nordic region, despite many shortcomings, is in a stronger position than many other developed economies. Nordic countries can demonstrate a strong tradition of adapting to economic pressures brought about by structural changes. They have also succeeded in mobilising much of the population in profitable economic activity, and in displaying very strong productivity.

But changes and improvements are needed. The pressure exerted by, not least, the three major challenges, will call for extensive and revolutionary thinking in a number of areas. Six main points can be identified where the general need for reform in the Nordic countries is particularly crucial.

there must be a strong focus on child care, pre-school activities and compulsory schools. Teaching skills are a critical factor in the outcome of education and here, in particular, the economic position and social status of teachers play a big role. A comprehensive apprentice system should be built up, to utilise the talent that is perhaps not fully realised at upper secondary level. At university level, academic quality must always be given greatest priority. In working life, adult education and in-service training will become more important in a society where the knowledge base and technology are changing at an everincreasing pace.

Improved education is not just important for managing new circumstances on the labour market; it also has effects on equality, trust and coherence in society. A highly-skilled labour force is vital if the Nordic countries are to assert themselves in global competition. 

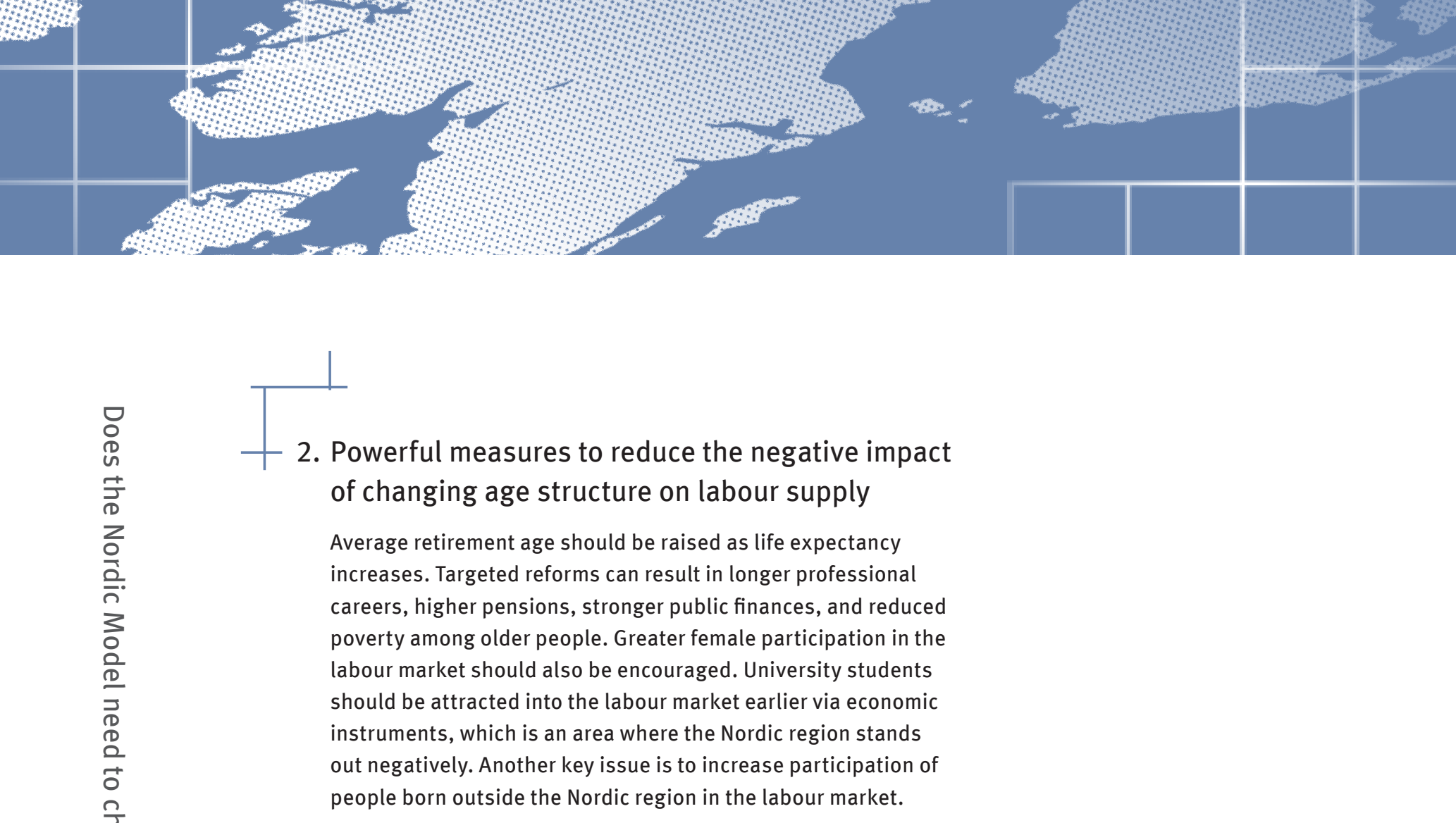

3. Minimise unemployment and direct the labour force towards the most productive jobs

These should be the most important objectives of labour market policy. On account of rapid technological changes, global competition for skills, and high macroeconomic volatility, salary flexibility is very important for keeping unemployment levels down. Some widening of income differences may be unavoidable if a future objective is high levels of employment. 


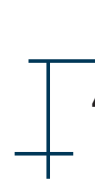

4. Promote innovative power and the ability to make rapid structural changes

Accepting "creative destruction" and remaining at the cutting edge of global technological development is key to maintaining a high standard of living. More efficient use of public funding in research and innovation activities is desirable. Specialising in certain fields of research and development is always a risk, but is also necessary for the small - in a global context - Nordic countries.

5. General tax level in relation to GNP likely to fall

Rather than tax increases, the discussion is more about the extent to which taxes must be reduced, as a result of the growing mobility of the most important tax bases. Tax system structures can be improved. Supply and mobility of the labour force, risk-taking and participation in global value chains should be stimulated. Reducing tax on labour and, instead, increasing it on property and consumption is desirable. The level of corporation tax must be competitive in international terms.

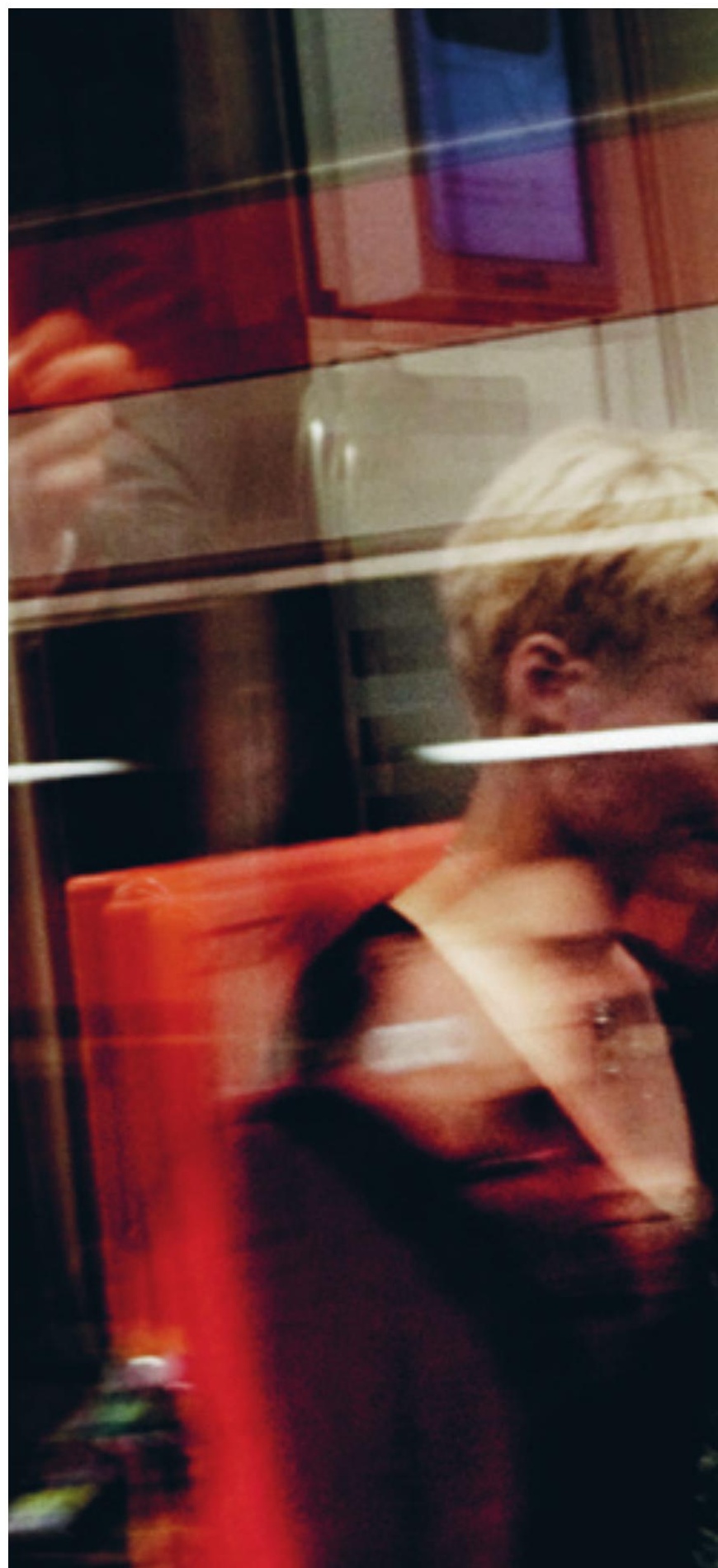




\section{1 \\ 6. Streamlining of the public sector must not be held back}

Even if the Nordic region stands up well in this area, although comparisons are difficult, there is much scope for improvement in all the Nordic countries. There are no simple answers for how to organise state institutions most efficiently, but successes can be attained through greater use of market mechanisms. Using new digital technology in public administration can also considerably reduce costs. Methods for evaluating the level of quality in public services must be improved, regardless of whether they are provided by private or public players.

Sound macroeconomic policies are vital for a functioning society - experiences show that a poorly managed macroeconomy can cause severe damage. High levels of external debt and permanently high levels of unemployment become a long-term inheritance transferred to future generations. There must be constant checks in place to ensure that tax credits are kept under control and that banks operate inside the set frameworks.
One necessary condition for stable finances is to ensure there is sufficient capacity in the budget to withstand traditional economic cycles. It may be difficult - even in the best of times - to build up sufficient buffers if the digital revolution, globalisation and increasing life expectancy start to exert real pressure. It can also be difficult to determine whether a recession is cyclical, therefore necessitating temporary stimulation measures, or permanent, necessitating adaptation to a new situation. Independent expert groups can help to determine this, and ensure that excessive debts do not build up during periods of recession. Experiences from such economic councils in Denmark and Sweden are encouraging. 


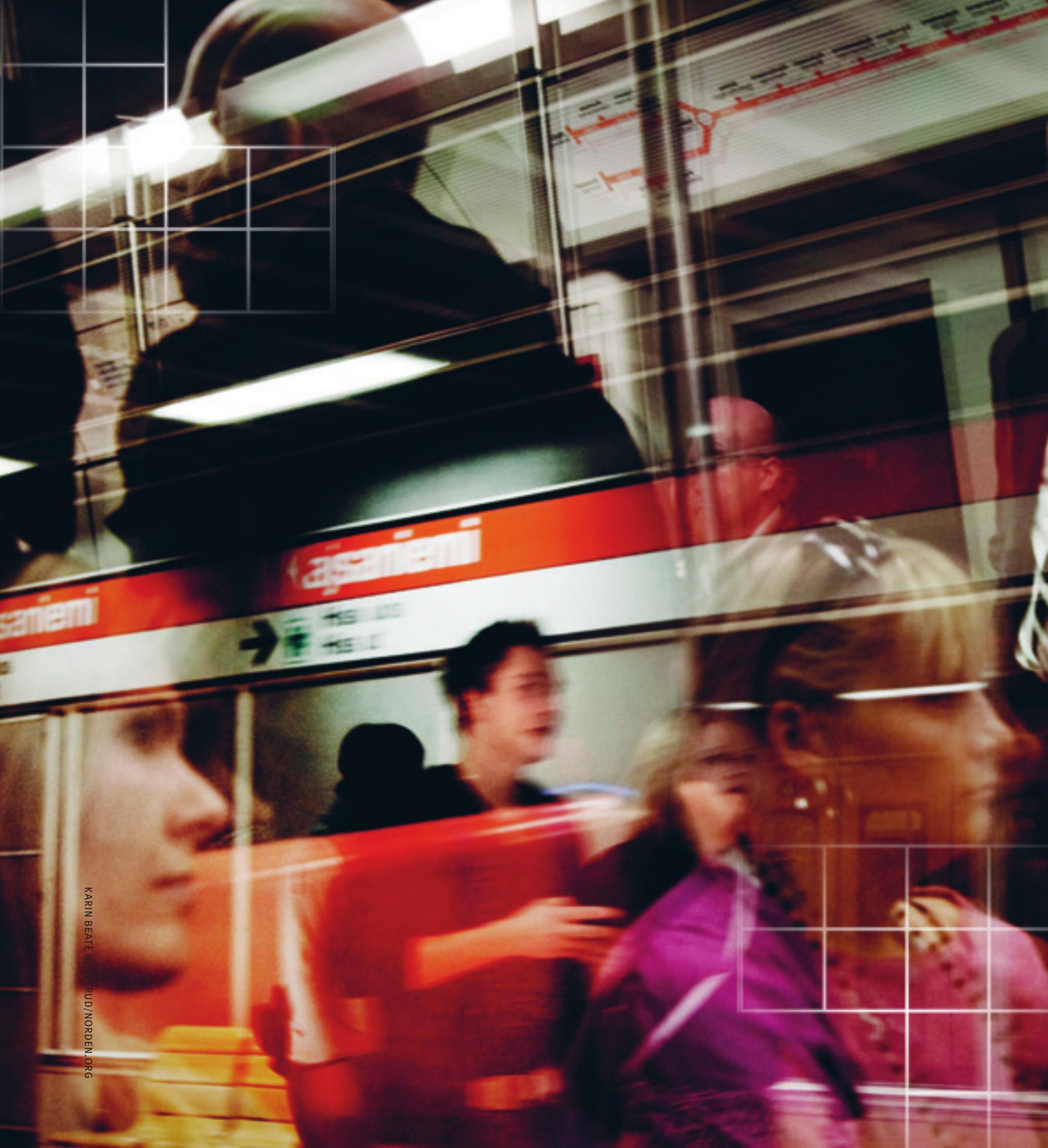




\section{Weaknesses and strengths of the Nordic countries, and reform proposals}

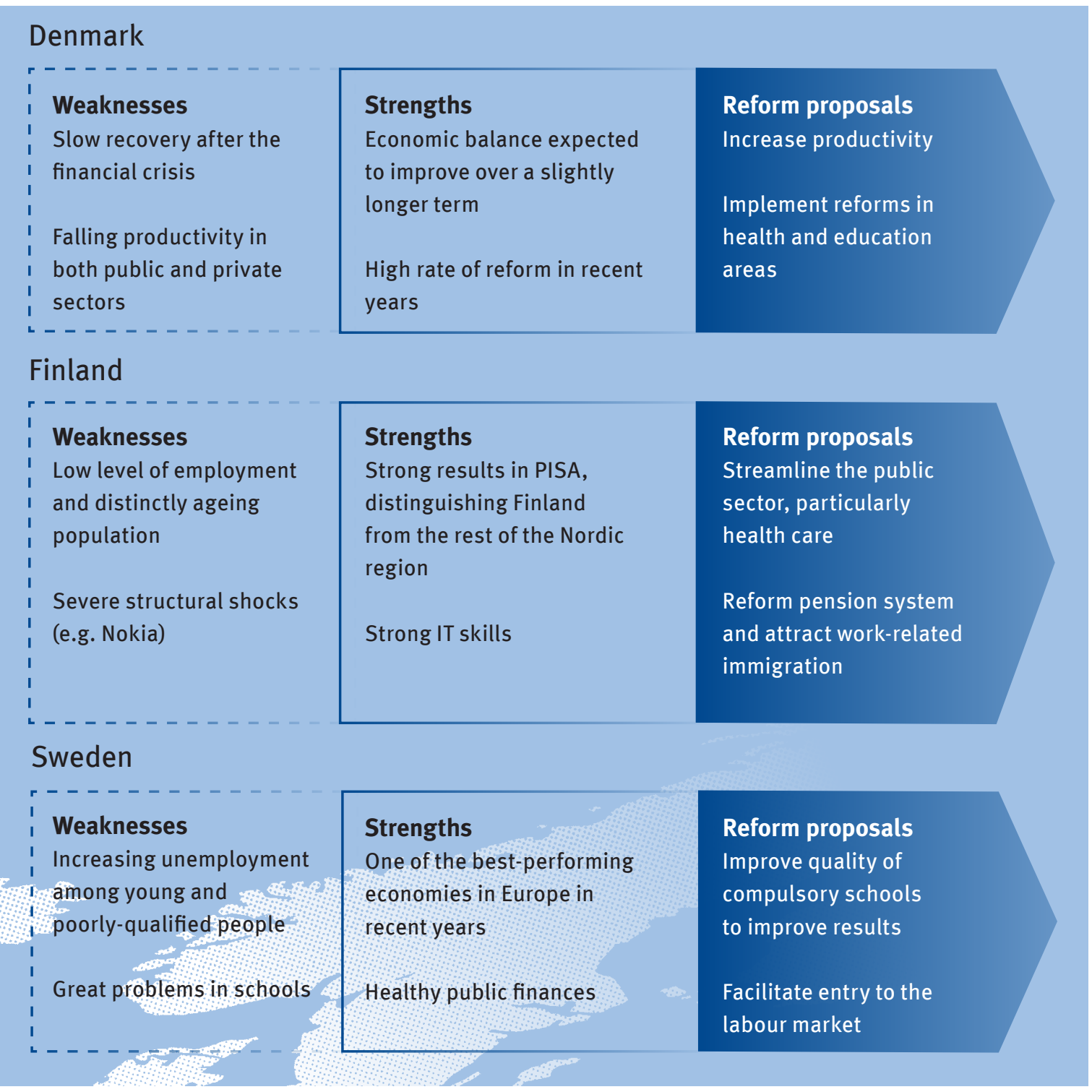




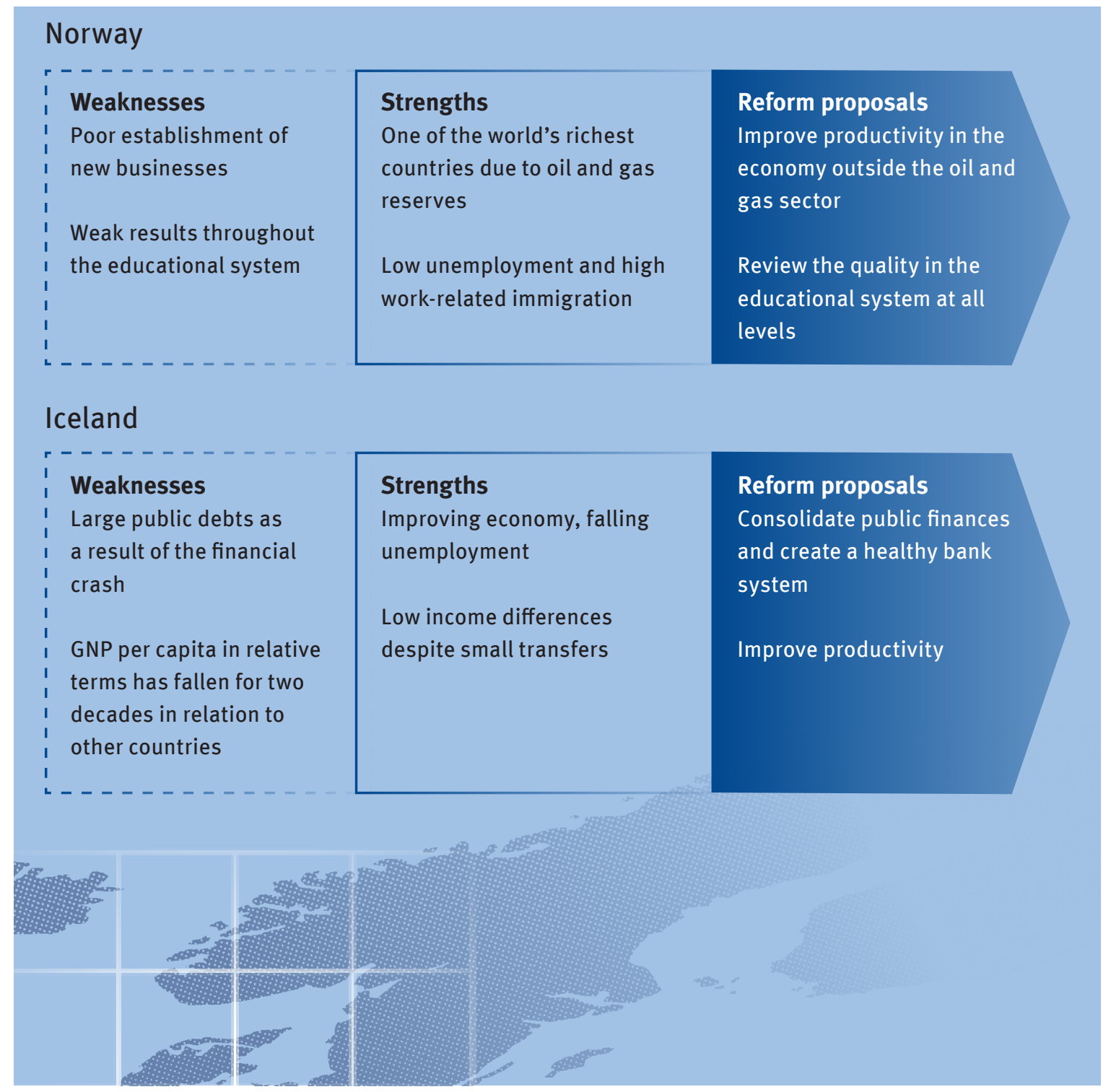




\section{Afterword}

Implementing reforms that are necessary in the long term but painful in the short perspective is never easy, particularly as forecasting the outcome of political measures and reforms is difficult. Consequently, an openness to new ideas and methods is needed, but also humility and an ability to take stock and rethink in line with changing circumstances. It is invaluable if a society can carefully, critically and comprehensively interpret the results of political reforms, and then draw conclusions about where to go from there.

The above reform proposals will, in all likelihood, improve the ability of the Nordic countries to retain, or even increase, already high levels of employment. Hopefully, the proposals will also lead to an increase in productivity that will stand up well in international competition. A certain widening of income differences is probably unavoidable - global competition and technological development will put pressure on market incomes and widen differences. At the same time, income transfers cannot be increased, and may even have to be reduced, but such a change need not be so great if we continue to attain high levels of employment and if the public sector is successfully streamlined.

The Nordic Model does not require dismantling and reassembly. With some adjustment, fine calibration and a clearer focus, the Nordic model can continue along its successful path. 

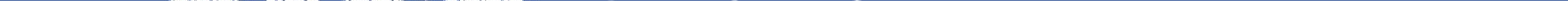


\section{nordon}

Nordic Council of Ministers

Ved Stranden 18

DK-1061 Copenhagen K

www.norden.org

\section{Does the Nordic Model need to change?}

The Nordic Model is a well-established concept in the world. It explains, for example, the successes of the Nordic countries in recent times, not least in various economic terms. But how does the model work in these times of globalisation, and does it have a future? Here, the consequences of digitalisation, globalisation and the ageing population are described, and proposals presented for what needs to be reformed in the Nordic countries to ensure that the model has a future. 